\title{
Evaluation of atherosclerosis in patients with chronic kidney disease by measuring carotid intima media thickness: An observational study from a tertiary care center in India
}

\author{
Lamsaka Lyngdoh', Bodhibrata Banerjee ${ }^{2}$, Sampurna Chowdhury ${ }^{3}$, Rishav Mukherjee ${ }^{4}$, \\ Subhendu Bikash Naiya ${ }^{5}$, Raja Bhattacharya ${ }^{6}$ \\ 1,3,4,5 Senior Resident, ${ }^{2}$ Post Graduate Trainee, ${ }^{6}$ Associate Professor, Department of General Medicine, Medical College, \\ Kolkata, West Bengal, India
}

A B S T R A C T

Background: Chronic kidney disease (CKD) is associated with a substantial cardiovascular mortality and morbidity. Besides other factors, accelerated atherosclerosis plays a significant role in this. Carotid intima media thickness (CIMT) is an index of systemic atherosclerosis. By measuring the CIMT with the help of B mode ultrasound at common carotid artery, the overall atherosclerotic burden in CKD patients can be estimated. Accordingly patients at increased risk of premature mortality can be identified so that timely intervention can be taken. Aims and Objectives: The aim of the study was to measure the CIMT at the level of common carotid artery by B mode ultrasound for estimation of atherosclerotic burden in patients with CKD. Materials and Methods: It is a hospital based observational cross-sectional study involving 70 patients carried out in the department of General Medicine of Medical College and Hospital, Kolkata for a period of 1 year. Patients were selected on the basis of certain inclusion and exclusion criteria. They were evaluated based on clinical history, disease duration, physical examination findings and certain investigation parameters such as complete hemogram, renal function tests, serum potassium, lipid profile, urinalysis, urine for albumin-creatinine ratio, ultrasonography of kidney-ureter-bladder, and CIMT value as measured by $\mathrm{B}$ mode ultrasound of carotid artery. The data collected were analyzed with a suitable statistical analysis software package. Range, frequencies, percentage, mean, standard deviation, and $\mathrm{P}$ value were calculated. $\mathrm{P}<0.05$ was taken as significant. Results: The study showed a strong correlation between CIMT and BMI $(r=0.533, \mathrm{P}<0.001)$. CIMT for serum triglyceride levels $(\geq 150 \mathrm{mg} / \mathrm{dl})$ were significantly $(P<0.001)$ high in patients (mean $\pm S D=1.45 \pm 0.559$ ) $\mathrm{mg} / \mathrm{dl}$ in comparison with serum triglyceride levels $(<150 \mathrm{mg} / \mathrm{dl})(0.98 \pm 0.380 \mathrm{mg} / \mathrm{d})$. Patients with high cholesterol of $\geq 200 \mathrm{mg} / \mathrm{dl}$ have a higher CIMT of $1.56 \pm 0.574$ with $\mathrm{P}<0.001$. There is statistically significant relation of LDL with respect to mean CIMT as $\mathrm{P}<0.001$ at $1 \%$ level of significance. Hence, mean CIMT is more in LDL $(\geq 130)$ than in LDL $(<130)$. CIMT for HDL levels $(<40 \mathrm{mg} / \mathrm{dl}$ ) were high in CKD (mean $=1.53 \pm 0.518 \mathrm{mg} / \mathrm{dl}$ ) patients compared to HDL levels $(\geq 40 \mathrm{mg} / \mathrm{dl})$ (mean $=10.88 \pm 0.291)$. It was found that mean CIMT was higher in the later stages of kidney disease (Stage 3B, 4 and Stage 5) as compared to early stages (Stages 1, 2, and 3). We also found that the Mean CIMT (1.214 \pm 0.531 was higher in patients with CKD compared to sonographically defined normal value $(<0.9 \mathrm{~mm})$. Hence, CKD patients who have traditional risk factors for atherosclerosis such as higher $\mathrm{BMI}$, higher serum total cholesterol level, higher serum triglyceride level, higher serum LDL level, and lower serum HDL level have a higher value of CIMT. Conclusion: B-mode ultrasound is a non-invasive sensitive tool for assessment of CIMT. Since CKD is associated with accelerated atherosclerosis and subsequent increased cardiovascular mortality, this modality may help us to identify patients with atherosclerotic burden so that timely intervention can be taken to reduce future cardiovascular complications in CKD patients.

Key words: Atherosclerosis; Carotid intima media thickness; Chronic kidney disease; Dyslipidemia; Ultrasonography

\section{Access this article online}

Website:

http://nepjol.info/index.php/AJMS DOI: 10.3126/ajms.v12i12.39547

E-ISSN: 2091-0576

P-ISSN: 2467-9100

Copyright (c) 2021 Asian Journal of Medical Sciences

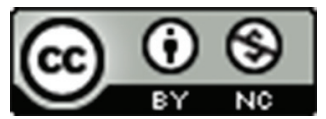

This work is licensed under a Creative Commons Attribution-NonCommercial 4.0 International License. 


\section{INTRODUCTION}

Chronic kidney disease (CKD) is a serious condition associated with premature mortality, decreased quality of life, and increased health-care expenditures. ${ }^{1}$ Many patients with CKD have cardiovascular disease. They die prematurely from this condition instead of surviving long enough to face dialysis or transplantation. Patients with CKD tend to have an excess of traditional risk factors for cardiovascular disease, such as hypertension, diabetes, and hyperlipidaemia. ${ }^{2-4}$ Renal disease also promotes cardiovascular injury by different mechanisms. These include dysregulation of calcium and phosphate metabolism, vascular calcification, anemia, dyslipidemia, hyperhomocysteinemia, and endothelial dysfunction leading to accelerated atherosclerosis. The atherosclerosis is often asymptomatic. So a direct examination of vessel wall is necessary to detect affected individuals in early stages. According to International Atherosclerosis Project, the process occurs simultaneously in carotid, cerebral, and coronary artery.

Carotid intima-medial thickness (CIMT) is well-established index of systemic atherosclerosis. ${ }^{5,6}$ Studies have shown that this is an independent predictor of cardiovascular mortality in CKD population..$^{711}$ Measurement CIMT of the common carotid artery by B-mode ultrasound is a suitable non-invasive method to visualize the arterial walls for monitoring the early stages of atherosclerotic process. ${ }^{12-15}$ It is also helpful to decide the appropriate method of treatment, either surgical or medical in patients with carotid artery stenosis. ${ }^{16-18}$

\section{Aims and objectives}

The aim of the study was to identify the at risk population among CKD patients with regard to atherosclerotic burden by assessment of CIMT by B mode ultrasound of common carotid artery.

\section{MATERIALS AND METHODS}

This was an observational cross-sectional study conducted in the inpatient and outpatient department of General Medicine, Medical College and Hospital, Kolkata from January 2019 to August 2020. Permission was obtained from the Institutional Ethics Committee.

The study population was clinically stable adult patients of either sexes having CKD coming to Medical college within the stipulated time period $(n=70)$. Focused history taking including the demographic profile of the patients, clinical history with duration of disease, medication history, disease specific therapy, and its duration along with clinical examination was done. Investigations were performed which included complete and clinical examination were done. Investigations including fasting lipid profile, urea, creatinine, potassium, urinalysis study, urine albumincreatinine ratio (ACR), hemoglobin, USG whole abdomen with kidney, ureter, bladder, and CIMT as measured by USG Doppler study were carried out.

All ultrasound measurements were performed at the Dept. of Radiology, Medical College, Kolkata. CIMT was assessed at three levels on each side: Common carotid artery, bulb, and internal carotid artery. The mean CIMT was defined as the mean of the three CIMT measurements on each side, According to current sonographic criteria, a normal value is defined as CIMT $<0.9 \mathrm{~mm}$. In addition, the number and size of carotid atherosclerotic plaques were also assessed. The patients were categorized on the basis of age, sex, disease severity, and common risk factors. CIMT values obtained were correlated with the above parameters along with markers of atherosclerosis. The data collected were tabulated in a master chart.

\section{Statistical analysis}

Data analysis was performed with a commercially available statistical analysis software package (SPSS 27.0 for Windows; SPSS; Chicago, IL, USA). The Range, frequencies, percentage, mean, standard deviation, and $\mathrm{P}$ value were calculated. $\mathrm{P}<0.05$ was taken as significant.

\section{RESULTS}

70 patients were included in the study. All of them had CKD (according to National kidney foundation). The patients were studied for CIMT in relation with the different stages of CKD and also with cardiovascular risk factor such as age, sex, BMI, and dyslipidemia.

Out of 70 CKD patients, $39(55.7 \%)$ were males, and $31(44.3 \%)$ were females. Baseline characteristics of cases are mentioned in Table 1. The mean value of these characteristics are shown in Figure 1. The distribution of age and sex of the patients are shown in Table 2 and Table 3 respectively. The same is shown in pictorial form in Figure 2 and Figure 3 respectively. The mean age of study population was $58.37 \pm 12.193$ years (34-90 years). Mean CIMT level was $1.214 \pm 0.531 \mathrm{~mm}$.

In present study, when CKD patients were staged, then $14(20.0 \%)$ of the patients were in the Stage 5, $11(15.7 \%)$ were in Stage 4. About $64.3 \%$ of the patients were in early stage of kidney disease (Stages 1, 2, and 3A and 3B) (Table 4 and Figure 4). 


\begin{tabular}{lc}
\multicolumn{2}{l}{ Table 1: Baseline characteristics of different } \\
parameters \\
\hline Baseline parameters & Mean \pm SD \\
\hline Age (years) & $58.37 \pm 12.193$ \\
BMl & $26.46 \pm 2.376$ \\
Total Cholesterol (mg/dl) & $207.10 \pm 50.632$ \\
Triglycerides $(\mathrm{mg} / \mathrm{dl})$ & $164.57 \pm 42.732$ \\
LDL (mg/dl) & $132.01 \pm 46.519$ \\
HDL (mg/dl) & $40.91 \pm 9.270$ \\
VLDL $(\mathrm{mg} / \mathrm{dl})$ & $32.94 \pm 8.551$ \\
Carotid intima media thickness $(\mathrm{mm})$ & $1.214 \pm 0.531$ \\
UREA (mg/dl) & $72.97 \pm 58.567$ \\
CREA (mg/dl) & $2.83 \pm 3.511$ \\
Urine albumin-creatinine ratio $(\mathrm{mcg} / \mathrm{mg})$ & $185.24 \pm 137.315$ \\
K+ (mmol/L) & $4.16 \pm 0.766$ \\
Hb (g/dl) & $10.75 \pm 1.749$ \\
GFR value (ml/min/1.73 m) & $42.74 \pm 29.269$ \\
\hline
\end{tabular}

\begin{tabular}{|c|c|c|}
\hline Age & Frequency & Percent \\
\hline$\leq 40$ years & 4 & 5.7 \\
\hline $41-60$ years & 42 & 60.0 \\
\hline $61-80$ years & 20 & 28.6 \\
\hline$>80$ years & 4 & 5.7 \\
\hline Total & 70 & 100.0 \\
\hline
\end{tabular}

\begin{tabular}{|c|c|c|}
\hline Sex distribution & Number of patients & Percent \\
\hline Female & 31 & 44.3 \\
\hline Male & 39 & 55.7 \\
\hline Total & 70 & 100.0 \\
\hline
\end{tabular}

$\begin{aligned} & \text { Table 4: Distribution of the subject according to } \\
& \text { stages of CKD }\end{aligned}$
\begin{tabular}{lcc}
\hline CKD stages & Number of patients & Percentage \\
\hline Stage1 & 6 & 8.6 \\
Stage 2 & 16 & 22.9 \\
Stage 3A & 5 & 7.1 \\
Stage 3B & 18 & 25.7 \\
Stage 4 & 11 & 15.7 \\
Stage 5 & 14 & 20.0 \\
Total & 70 & 100.0 \\
\hline CKD: chronic kidney disease & &
\end{tabular}

From Table 5, it is observed that there is no direct corelation of the CIMT and eGFR (CC $=-0.169[\mathrm{P}=0.163])$. However, CIMT values are more in later stages of CKD (Stage 3B, 4, and 5) compared to early stages (Stages 1, 2, and 3A) (Figure 5).

From Table 6, it is observed that there is statistically no significant relation of categories of age with respect to mean CIMT as the $\mathrm{P}>0.05$, at $5 \%$ level of significance. Mean CIMT is maximum in the age

\begin{tabular}{|c|c|}
\hline Stages of CKD & Mean CIMT \\
\hline Stage1 & $1.026 \mathrm{~mm}$ \\
\hline Stage 2 & 1.15 mm \\
\hline Stage 3A & $0.92 \mathrm{~mm}$ \\
\hline Stage 3B & $1.27 \mathrm{~mm}$ \\
\hline Stage 4 & $1.19 \mathrm{~mm}$ \\
\hline Stage 5 & $1.42 \mathrm{~mm}$ \\
\hline Correlation coefficient $(-0.169)$ & \\
\hline
\end{tabular}

Table 6: Significance of different parameters
(AGE) with respect to mean carotid intima media
thickness
\begin{tabular}{lccc} 
& & \\
\hline Parameter & Category & Mean \pm SD & P-value \\
\hline AGE & $\leq 40$ years & $1.21 \pm 0.187$ & 0.639 \\
& $41-60$ years & $1.23 \pm 0.546$ & \\
& $61-80$ years & $1.21 \pm 0.563$ & \\
& $>80$ years & $1.50 \pm 0.463$ & \\
\hline
\end{tabular}

\begin{tabular}{|c|c|c|c|}
\hline Parameter & Category & Mean $\pm S D$ & P-value \\
\hline SEX & $\begin{array}{l}\text { Male } \\
\text { Female }\end{array}$ & $\begin{array}{l}1.26 \pm 0.543 \\
1.16 \pm 0.519\end{array}$ & 0.441 \\
\hline
\end{tabular}

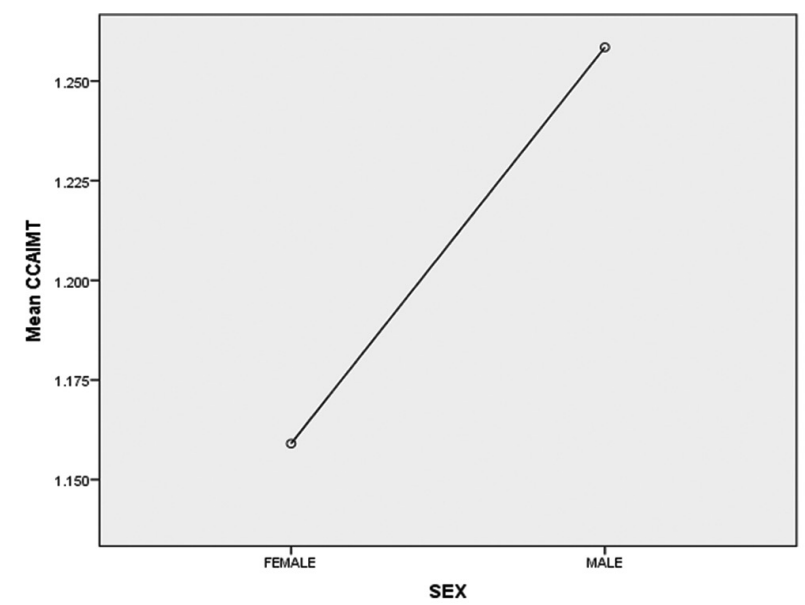

group more than 80 years and minimum in the age group of $61-80$ years.

From Table 7, it is observed that there is statistically no significant relation of Sex with respect to mean CIMT as the $\mathrm{P}>0.05$, at $5 \%$ level of significance. Mean CIMT is more in male than in female.

From Table 8 , it is observed that there is statistically significant relation of BMI with respect to mean CIMT 


\begin{tabular}{|c|c|c|c|}
\hline Parameter & Category & Mean $\pm S D$ & P-value \\
\hline BMI & $\begin{array}{l}\text { Non-obese } \\
\text { Obese }\end{array}$ & $\begin{array}{l}1.18 \pm 0.484 \\
1.67 \pm 0.915\end{array}$ & $0.044^{*}$ \\
\hline
\end{tabular}

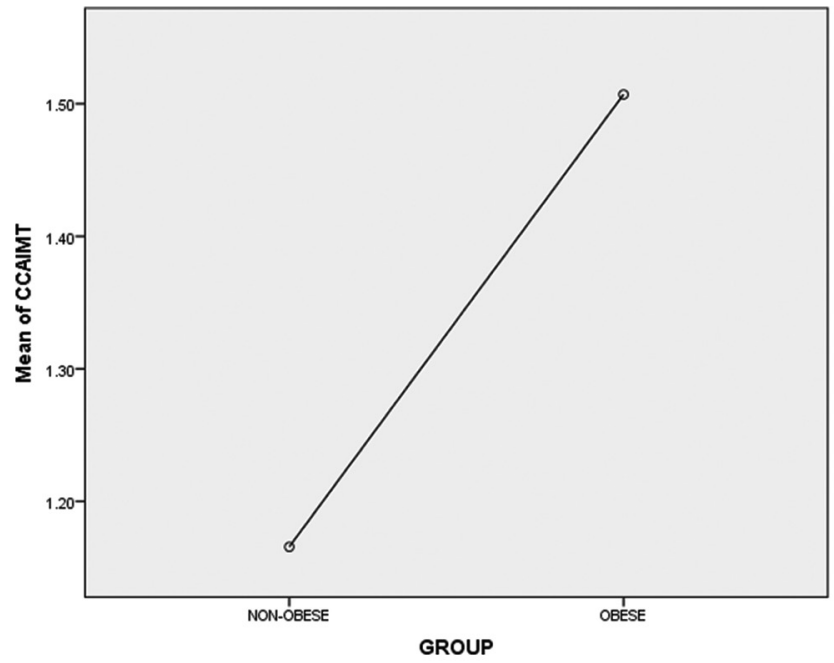

Table 9: Significance of different parameters (TC) with respect to mean carotid intima media thickness

\begin{tabular}{lccc} 
Parameter & Category & Mean \pm SD & P-value \\
\hline TOTAL & $<200$ & $1.02 \pm 0.399$ & $\mathrm{P}<0.001$ \\
CHOLESTEROL & $\geq 200$ & $1.56 \pm 0.574$ & \\
\hline
\end{tabular}

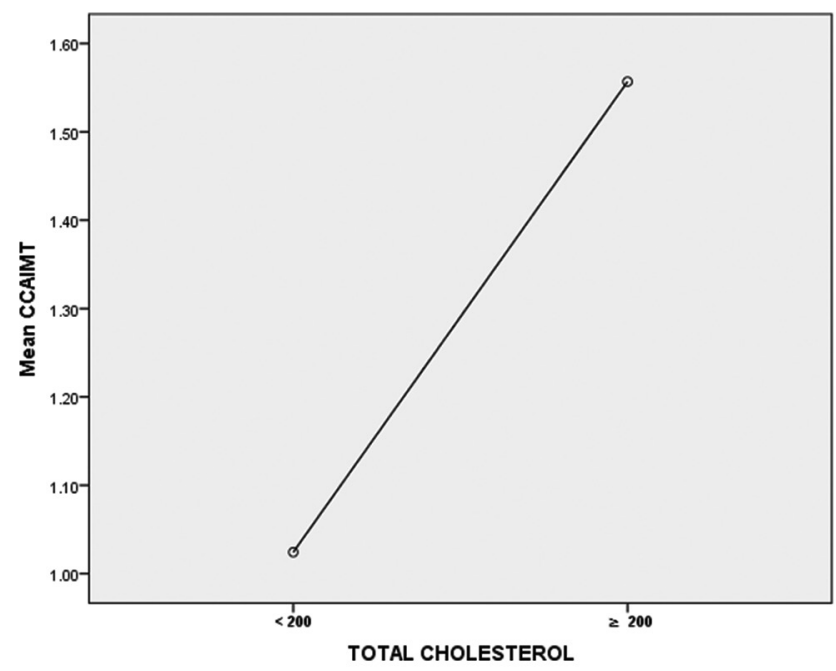

as the $\mathrm{p}<0.05$, at $5 \%$ level of significance. Mean CIMT is more in obese than in non-obese.

From Table 9, it is observed that there is statistically significant relation of total cholesterol with respect to mean

\begin{tabular}{|c|c|c|c|}
\hline Parameter & Category & Mean $\pm S D$ & P-value \\
\hline Triglycerides & $\begin{array}{l}<150 \\
\geq 150\end{array}$ & $\begin{array}{l}0.98 \pm 0.380 \\
1.45 \pm 0.559\end{array}$ & $P<0.001$ \\
\hline
\end{tabular}

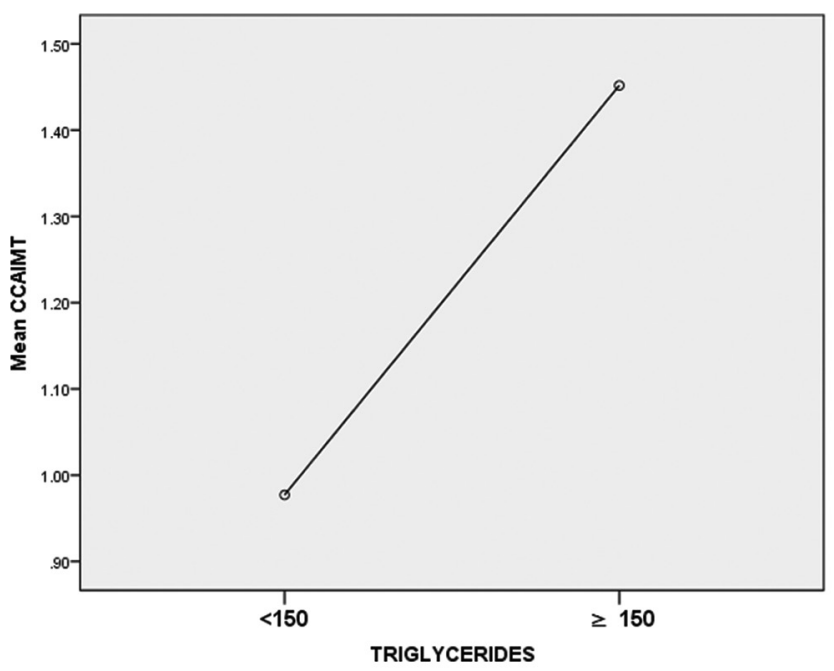

CIMT as the $\mathrm{P}<0.001$ at $1 \%$ level of significance. Mean CIMT is more in TC $(\geq 200)$ than in TC $(<200)$.

From Table 10, it is observed that there is statistically significant relation of triglycerides with respect to mean CIMT as the $\mathrm{P}<0.001$ at $1 \%$ level of significance. Mean CIMT is more in TG $(\geq 150)$ than in TC $(<150)$.

From Table 11 it is observed that there is statistically significant relation of HDL with respect to mean CIMT as the $\mathrm{P}<0.001$ at $1 \%$ level of significance. Mean CIMT is more in HDL $(<40)$ than in HDL $(\geq 40)$.

From Table 12, it is observed that there is statistically significant relation of LDL with respect to mean CIMT as the $\mathrm{P}<0.001$ at $1 \%$ level of significance. Mean CIMT is more in LDL $(\geq 130)$ than in LDL $(<130)$.

From Table 13, it is observed that there is statistically significant relation of VLDL with respect to mean CIMT as the $\mathrm{P}<0.01$ at $1 \%$ level of significance. Mean CIMT is more in VLDL $(\geq 130)$ than in VLDL $(<130)$.

When univariate correlation analysis between CIMT and study parameters of age, BMI, serum total cholesterol levels, serum triglyceride levels, serum HDL-C levels LDL-C and VLDL-C, urine ACR, etc., was performed in CKD patients in Table 14 , significant correlation $(\mathrm{P}<0.05)$ of CIMT was found with BMI, serum cholesterol and serum triglyceride levels, and serum HDL-C levels LDL-C and VLDL-C. 


\begin{tabular}{|c|c|c|c|}
\hline Parameter & Category & Mean $\pm S D$ & $\mathrm{P}$-value \\
\hline HDL & $\begin{array}{l}<40 \\
\geq 40\end{array}$ & $\begin{array}{l}1.53 \pm 0.518 \\
0.88 \pm 0.291\end{array}$ & $P<0.001$ \\
\hline
\end{tabular}

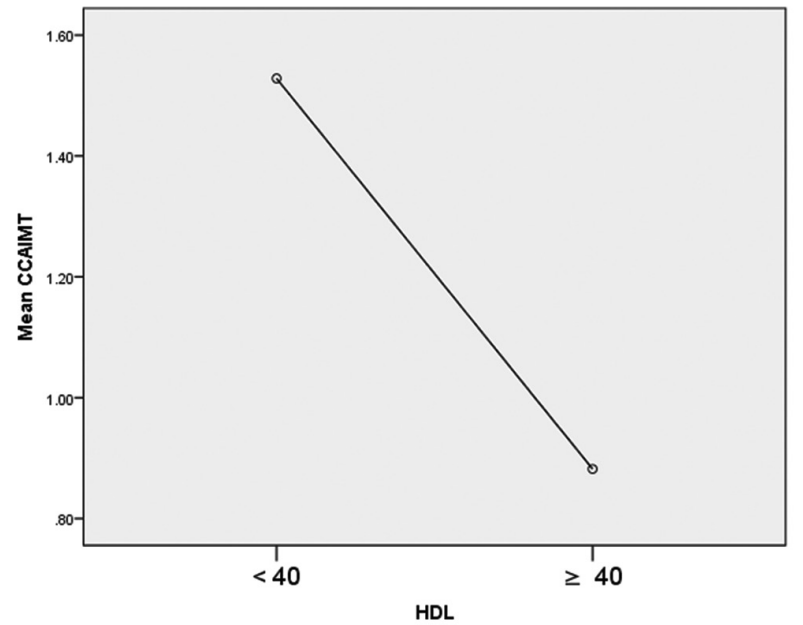

Table 12: Significance of different parameters
(LDL) with respect to mean carotid intima media
thickness
\begin{tabular}{lccc} 
& & \\
\hline Parameter & Category & Mean \pm SD & P-value \\
\hline LDL & $<130$ & $0.97 \pm 0.378$ & $P<0.001$ \\
& $\geq 130$ & $1.60 \pm 0.517$ & \\
\hline
\end{tabular}

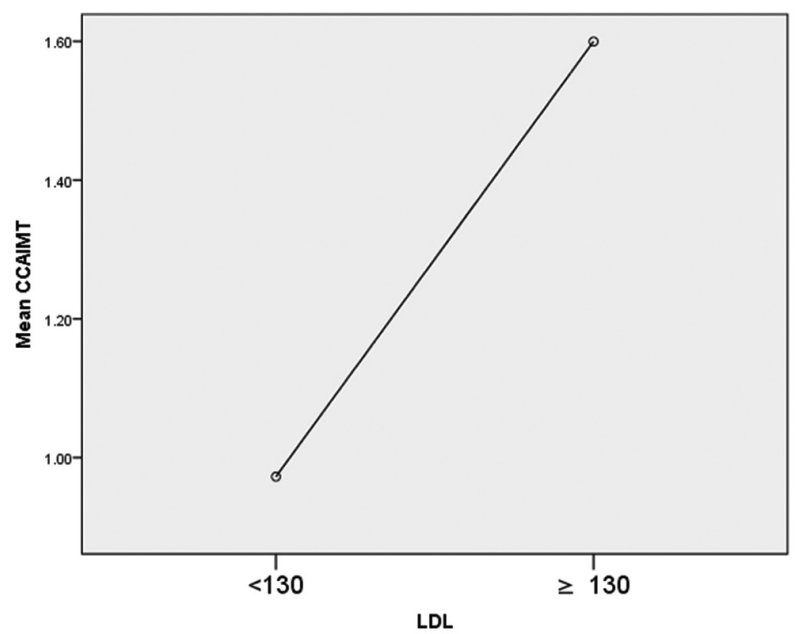

\section{DISCUSSION}

70 patients were included in our study. All of them had CKD (according to National kidney foundation). The patients were studied for CIMT in relation with the different stages of CKD and also with cardiovascular risk factor such as age, sex, BMI,

Table 13: Significance of different parameters
(VLDL) with respect to mean carotid intima
media thickness
\begin{tabular}{lccc}
\hline Parameter & Category & Mean \pm SD & P-value \\
\hline VLDL & $<30$ & $1.01 \pm 0.396$ & $0.005^{*}$ \\
& $\geq 30$ & $1.37 \pm 0.572$ & \\
\hline
\end{tabular}

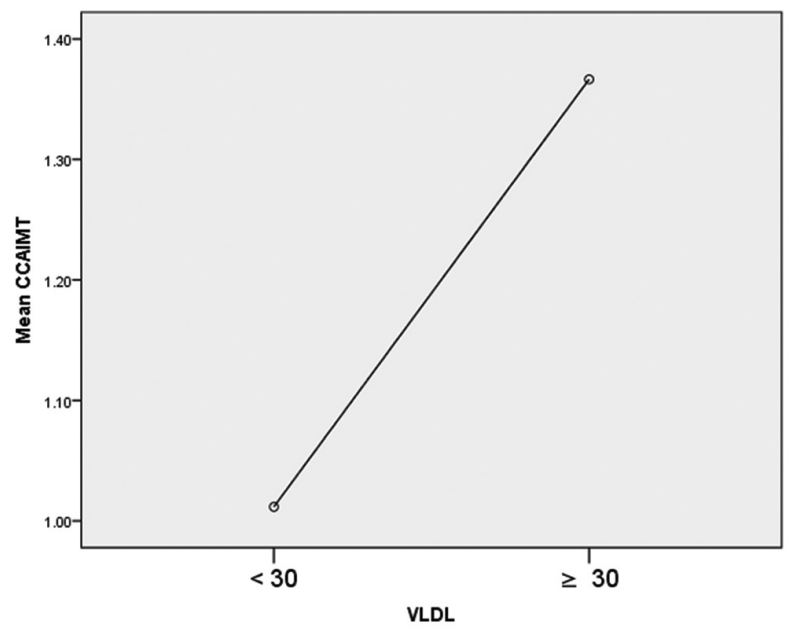

\begin{tabular}{lcc}
\multicolumn{3}{l}{$\begin{array}{l}\text { Table 14: Significance of correlation of } \\
\text { parameters with carotid intima media thickness }\end{array}$} \\
\hline Parameter & Correlation coeff $(\mathbf{r})$ & P-value \\
\hline Age (years) & 0.096 & $0.431(\mathrm{NS})$ \\
BMl & 0.533 & $\mathrm{P}<0.001(\mathrm{HS})$ \\
Total Cholesterol $(\mathrm{mg} / \mathrm{dl})$ & 0.564 & $\mathrm{P}<0.001(\mathrm{HS})$ \\
Triglycerides $(\mathrm{mg} / \mathrm{dl})$ & 0.419 & $\mathrm{P}<0.001(\mathrm{HS})$ \\
LDL $(\mathrm{mg} / \mathrm{dl})$ & 0.550 & $\mathrm{P}<0.001(\mathrm{HS})$ \\
$\mathrm{HDL}(\mathrm{mg} / \mathrm{dl})$ & -0.541 & $\mathrm{P}<0.001(\mathrm{HS})$ \\
VLDL $(\mathrm{mg} / \mathrm{dl})$ & 0.412 & $\mathrm{P}<0.001(\mathrm{HS})$ \\
UREA $(\mathrm{mmHg})$ & 0.011 & $0.930(\mathrm{NS})$ \\
CREA $(\mathrm{mg} / \mathrm{dl})$ & 0.046 & $0.705(\mathrm{NS})$ \\
Urine albumin-creatinine & 0.077 & $0.527(\mathrm{NS})$ \\
ratio $(\mathrm{mcg} / \mathrm{mg})$ & & \\
K+ (mmol/L) & 0.120 & $0.323(\mathrm{NS})$ \\
Hb $(\mathrm{gms} / \mathrm{dl})$ & -0.035 & $0.777(\mathrm{NS})$ \\
GFR value $(\mathrm{ml} / \mathrm{min} /$ & -0.169 & $0.163(\mathrm{NS})$ \\
$1.73 \mathrm{~m})$ & & \\
\hline
\end{tabular}

and dyslipidemia. In our study, the mean age of patients was $58.37 \pm 12.19$ years (range 34-90 years). Maximum number of subject was $42(60 \%)$ in age group of $41-60$ years. Out of 70 CKD patients, 39 (55.7\%) were males and 31 (44.3\%) were females. Mean CIMT level was $1.214 \pm 0.531 \mathrm{mmHg}$. The present study showed strong correlation between CIMT and $\mathrm{BMI}(\mathrm{r}=0.533, \mathrm{P}<0.001)$. In relation to sex, this study showed that males had higher CIMT values than females. According to lipid profile, this present study observed that CIMT for serum triglyceride levels ( $\geq 150 \mathrm{mg} / \mathrm{dl}$ ) were significantly $(\mathrm{P}<0.001)$ high in patients (mean $\pm \mathrm{SD}=1.45 \pm 0.559) \mathrm{mg} / \mathrm{dl}$ in comparison with serum triglyceride levels $(<150 \mathrm{mg} / \mathrm{dl})$ $(0.98 \pm 0.380 \mathrm{mg} / \mathrm{d})$. So also, patients with high cholesterol of 


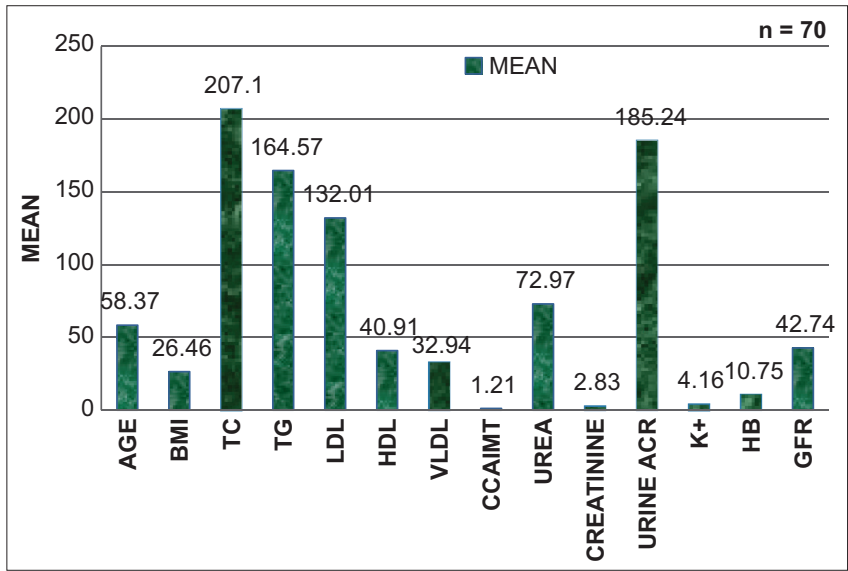

Figure 1: Mean value of baseline characteristics of different parameters

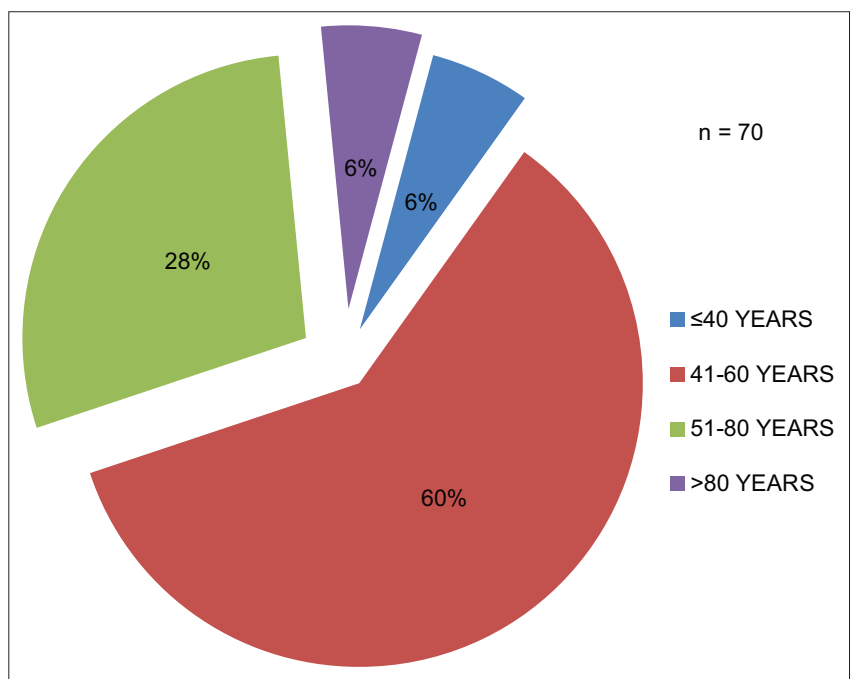

Figure 2: Age distribution among CKD patients. CKD: Chronic kidney disease

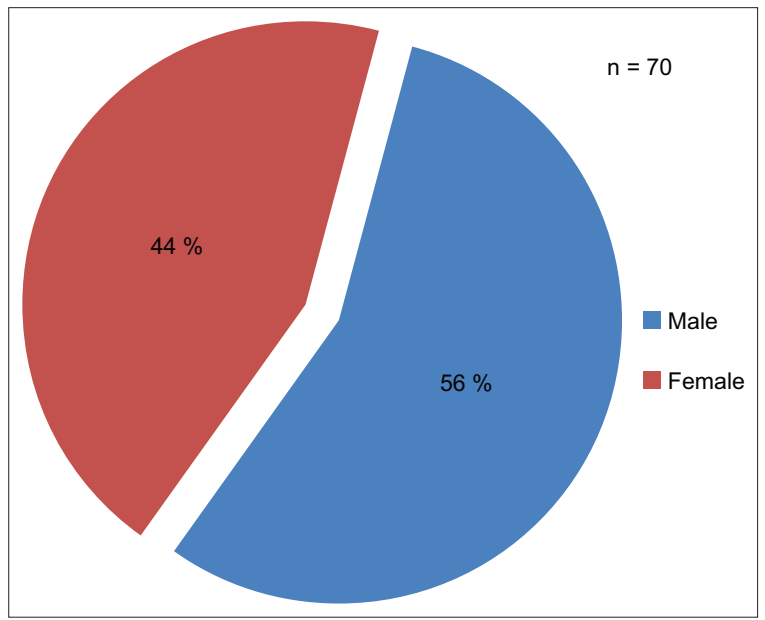

Figure 3: Sex distribution among CKD patients. CKD: Chronic kidney disease

$\geq 200 \mathrm{mg} / \mathrm{dl}$ have a higher CIMT of $1.56 \pm 0.574$ with $\mathrm{P}<0.001$.

There is statistically significant relation of LDL with respect to

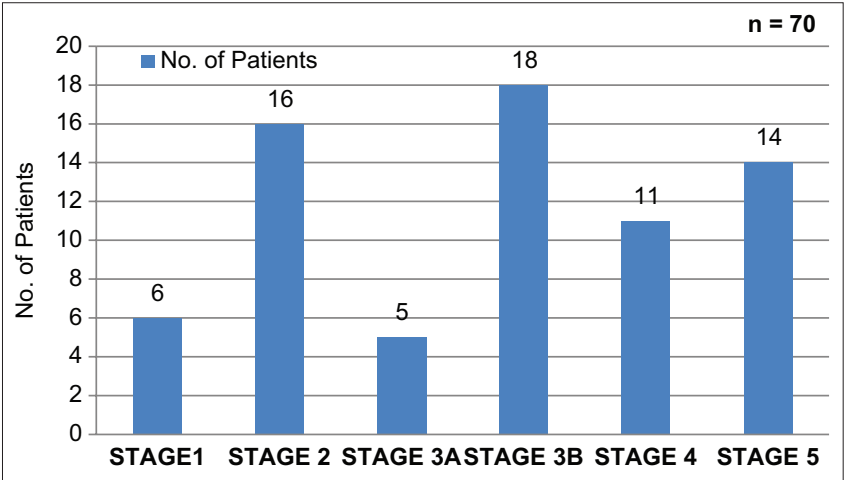

Figure 4: Distribution of the subject according to stages of CKD. CKD: Chronic kidney disease

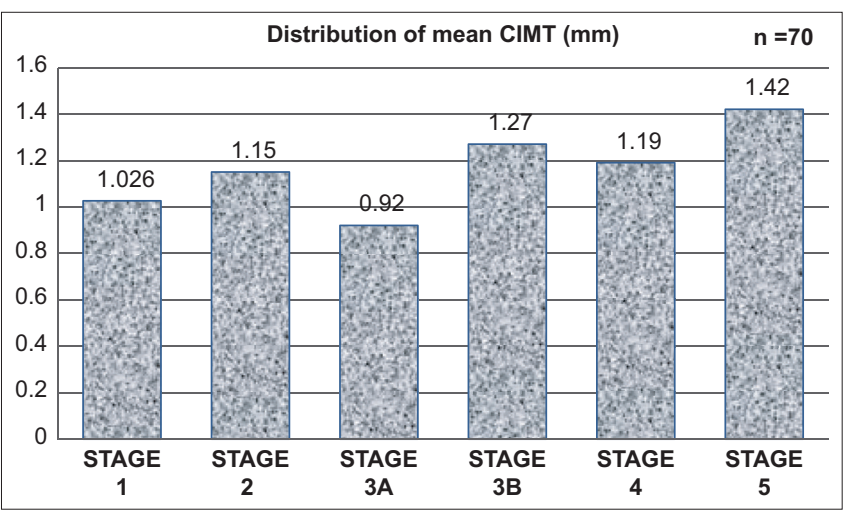

Figure 5: Distribution of the of mean CIMT according to stages of CKD. CIMT: Carotid intima media thickness, CKD: Chronic kidney disease

mean CIMT as the $\mathrm{P}<0.001$ at $1 \%$ level of significance. Hence, mean CIMT is more in LDL $(\geq 130)$ than in LDL $(<130)$. In the present study, CIMT for HDL levels $(<40 \mathrm{mg} / \mathrm{dl})$ were high in CKD (mean $=1.53 \pm 0.518 \mathrm{mg} / \mathrm{dl}$ ) patients compared to HDL levels $(\geq 40 \mathrm{mg} / \mathrm{dl}$ ) (mean=10.88 \pm 0.291$)$. It was found that mean CIMT was higher in the late stages of kidney disease (Stage 3B, 4 and Stage 5) as compared to early stages (Stage 1, 2, and 3A). According to age, our study showed that mean CIMT is higher in older patients with mean age of $58.37 \pm 12.93$ years. In present study, the mean CIMT level was $1.214 \pm 0.531 \mathrm{~mm}$. According to current sonographic criteria, a "normal" CIMT value is referred as $<0.9 \mathrm{~mm}$. Thus, the CIMT was higher in patients with CKD compared to sonographically define normal value.

\section{Limitations of the study}

A possible limitation of our study was the small sample size attributed to the stringent inclusion criterions of our study design. This was an institution based study and this could have introduced selection bias. The patients were followed up for the short term outcomes and this assessment may not represent the long-term therapeutic benefits. Extended follow-up period could have changed our outcomes. No blinding was done at any step in the study. 


\section{CONCLUSION}

From this study, we can conclude that CKD patients who have traditional risk factors for atherosclerosis such as higher BMI, higher serum total cholesterol level, higher serum triglyceride level, higher serum LDL level, and lower serum HDL level have a higher value of CIMT. $\mathrm{B}$-mode ultrasound is a non-invasive sensitive tool for assessment of CIMT. It can help us to identify patients with atherosclerotic burden so that timely intervention can be taken to reduce future cardiovascular complications in CKD patients.

\section{ACKNOWLEDGMENT}

Consent was taken from the patients for conducting the study after approval from the Institution Ethics Committee (IEC). We would like to express our gratitude to our patients for their cooperation. We would also like to thank the department of Radiodiagnosis, Pathology and Biochemistry for logistics support.

\section{REFERENCES}

1. Kumar A and Mitra JK. A study of carotid intimal-medial thickness in different stages of chronic kidney disease in relation to lipid profile. J Dent Med Sci. 2018;17(1):44-55.

2. Kumar KS, Lakshmi AY, Rao PS, Das GC and Kumar VS. Carotid intima-media thickness in patients with end-stage renal disease. Indian J Nephrol. 2009;19(1):13-14.

https://doi.org/10.4103/0971-4065.50674

3. Baldassarre D, Amato $M$, Bondioli A, Sirtori $C R$ and Tremoli E. Carotid artery intima-media thickness measured by ultrasonography in normal clinical practice correlates well with atherosclerosis risk factors. Stroke. 2000;31(10):2426-2430. https://doi.org/10.1161/01.STR.31.10.2426

4. Brzosko S, Lebkowska U, Malyszko J, Hryszko T, KrauzeBrzosko $\mathrm{K}$ and Mysliwiec M. Intima media thickness of common carotid arteries is associated with traditional risk factors and presence of ischemic heart disease in hemodialysis patients. Physiol Res. 2005;54(5):497.

5. Paul J, Dasgupta S and Ghosh MK. Carotid artery intima media thickness as a surrogate marker of atherosclerosis in patient with chronic renal failure on hemodialysis. North Am J Med Sci. 2012;4(2):77-80.

https://doi.org/10.4103/1947-2714.93379

6. Roxana ON, Balanescu S, Constantinescu D, Calmac L, Marinescu M and Dorobantu M. Imaging atherosclerosis by carotid intima-media thickness in vivo: How to, where and in whom? Maedica. 2012;7(2):153-162.

7. Hinderliter A, Padilla RL, Gillespie BW, Levin NW, Kotanko P, Kiser M, et al. Association of carotid intima-media thickness with cardiovascular risk factors and patient outcomes in advanced chronic kidney disease: The RRI-CKD study. Clin Nephrol. 2015;84(1):10-20.

https://doi.org/10.5414/CN108494

8. Chhajed N, Chandra BS, Shetty MS and Shetty C. Correlation of carotid intimal-medial thickness with estimated glomerular filtration rate and cardiovascular risk factors in chronic kidney disease. Saudi J Kidney Dis Transplant. 2014;25(3):572-576.

https://doi.org/10.4103/1319-2442.132186

9. Benedetto FA, Mallamaci F, Tripepi G and Zoccali C. Prognostic value of ultrasonographic measurement of carotid intima media thickness in dialysis patients. J Am Soc Nephrol. 2001;12(11):2458-2464.

https://doi.org/10.1681/ASN.V12112458

10. George JM, Bhat $\mathrm{R}$ and Pai KM. The carotid intima media thickness: A predictor of the clincal coronary events. J Clin Diagn Res. 2013;7(6):1082-1085.

https://doi.org/10.7860/JCDR/2013/4767.3029

11. Ekart R, Hojs R, Hojs-Fabjan $T$ and Balon BP. Predictive value of carotid intima media thickness in hemodialysis patients. Artif Organs. 2005;29(8):615-619.

https://doi.org/10.1111/j.1525-1594.2005.29098.x

12. Howard G, Sharrett AR, Heiss G, Evans GW, Chambless LE, Riley WA, et al. Carotid artery intimal-medial thickness distribution in general populations as evaluated by B-mode ultrasound. ARIC Investigators. Stroke. 1993;24(9):1297-1304. https://doi.org/10.1161/01.STR.24.9.1297

13. Ludwig $M$, von Petzinger-Kruthoff $A$, Von Buquoy $M$ and Stumpe KO. Intima media thickness of the carotid arteries: early pointer to arteriosclerosis and therapeutic endpoint. Ultraschall in der Medizin (Stuttgart, Germany: 1980) 2003;24(3):162-174. https://doi.org/10.1055/s-2003-40058

14. Pignoli P, Tremoli E, Poli A, Oreste P and Paoletti R. Intimal plus medial thickness of the arterial wall: A direct measurement with ultrasound imaging. Circulation. 1986;74(6):1399-1406. https://doi.org/10.1161/01.CIR.74.6.1399

15. Paul J, Shaw K, Dasgupta S and Ghosh MK. Measurement of intima media thickness of carotid artery by B-mode ultrasound in healthy people of India and Bangladesh, and relation of age and sex with carotid artery intima media thickness: An observational study. J Cardiovasc Dis Res. 2012;3(2):128-131.

https://doi.org/10.4103/0975-3583.95367

16. Kasliwal RR, Kaushik M, Grewal HK and Bansal M. Carotid ultrasound for cardiovascular risk prediction: From intimamedia thickness to carotid plaques. J Indian Acad Echocardiogr Cardiovasc Imaging. 2017;1(1):39-46.

17. Patel ML, Radheyshyam AV, Sachan R and Kamal R. Impact of carotid intima-media thickness on long-term outcome in hemodialysis patients. North Am J Med Sci. 2015;7(6):281-287. https://doi.org/10.4103/1947-2714.159339

18. Margekar V, Thakur S, Jatav OP, Tiwari D, Gupta M and Yadav P. Carotid intimal medial thickness (CIMT) in patients of chronic kidney disease (CKD) and its association with CKD staging. J Contemp Med Res. 2020;7(3):C7-C9. https://doi.org/10.21276/ijcmr.2020.7.3.6 
Authors Contribution:

LL- Concept and design of the study, prepared first draft of manuscript; RB- Concept, coordination, statistical analysis and interpretation, preparation of manuscript and revision of the manuscript; BB- Interpreted the results; reviewed the literature and manuscript preparation; SC- Preparation and revision of the manuscript; RM- Preparation and revision of the manuscript; SBN- Preparation and revision of the manuscript.

Work attributed to:

Medical College, Kolkata - 700 073, West Bengal, India.

Orcid ID:

Dr. Lamsaka Lyngdoh - (1) https://orcid.org/0000-0003-1639-5820

Dr. Bodhibrata Banerjee - (1) https://orcid.org/0000-0002-1520-5258

Dr. Sampurna Chowdhury - (i) https://orcid.org/0000-0002-5010-7565

Dr. Rishav Mukherjee - (10 https://orcid.org/0000-0001-5883-2908

Dr. Subhendu Bikash Naiya - (D) https://orcid.org/0000-0001-9759-7453

Dr. Raja Bhattacharya - io https://orcid.org/0000-0002-2159-9708

Source of Funding: The study subjects did not bear any financial burden related to this study. All procedures and investigations were performed at the institute, in close collaboration with the Department of Medicine, Radio-diagnosis and Biochemistry, Medical College, Kolkata, Conflicts of Interest: None. 